\title{
Incontinentia pigmenti with sensorimotor polyneuropathy: A novel association
}

Sir,

We report a patient with Incontinentia Pigmenti (IP) and peripheral neuropathy, an association not reported earlier.

A 16-year-old girl presented with $3^{1 / 2}$ years history of dragging of left foot and inability to grip slippers, and $2^{1 / 2}$ years history of weakness of hands followed by proximal weakness of lower limbs and numbness of hands and feet. She had pigmentation of left half of body since birth, global developmental delay and a congenital dermoid cyst of the scalp removed at $1 \frac{1}{2}$ years of age. On examination, there was left hemiatrophy and hyperpigmentation along the lines of Blaschko over the left upper limb, trunk and lower limb, some showing a Chinese check-board pattern consistent with the diagnosis of $\mathrm{IP}^{[1]}$ [Figure 1]. She had mild mental retardation and pigmentary retinopathy. There was bilateral pes cavus, hammer toes, flexion contractures of fingers at proximal interphalangeal joint, wasting of small muscles of hands, spasticity of lower limbs and moderate distal weakness of upper and lower limbs. There was a $25 \%$ reduction of pain and touch sensations in the upper limbs distal to midforearm, and lower limbs distal to the knees, impaired position sense in all limbs and vibration over toes, areflexia and flexor plantars bilaterally. Her stance was wide-based with high steppage, ataxic gait. Systemic examination was normal.

Nerve conduction studies showed unrecordable median, ulnar and sural sensory nerve action potentials, with prolonged latencies and reduced amplitudes of the common peroneal and posterior tibial compound motor action potentials. Magnetic resonance imaging (MRI) of brain showed a parenchymal cyst in the left hippocampus. Histopathological evaluation 
of sural nerve showed chronic uniform axonopathy (predominantly large fiber) with mild regenerative activity [Figure 2]. These features were consistent with hereditary neuropathy of axonal type. She was not exposed to toxins, not diabetic, had normal liver and renal functions, normal hemogram, ESR of $40 \mathrm{~mm} / \mathrm{h}$, negative RA factor, LE cell and ANA, and no systemic symptoms to suggest any acquired cause of neuropathy.

The neuroectodermal manifestation of IP involves the skin, hair, teeth, nails, eyes and the central nervous system. ${ }^{[2,3]}$ Early mental subnormality, spasticity, hemiatrophy, cystic lesion in hippocampus and pigmentary retinopathy were the central nervous system anomalies in our patient. Peripheral nervous system abnormalities have not been reported in IP. Peripheral nerves are derivatives of the neuroectodermal placode while the perineurium develops from the mesoderm. ${ }^{[4]}$ Hence, the association of peripheral neuropathy in our patient with IP can be explained by the hypothesis of common embryological origin from the neuroectoderm. The presence of a later onset of polyneuropathy in adolescence is also unusual considering that most
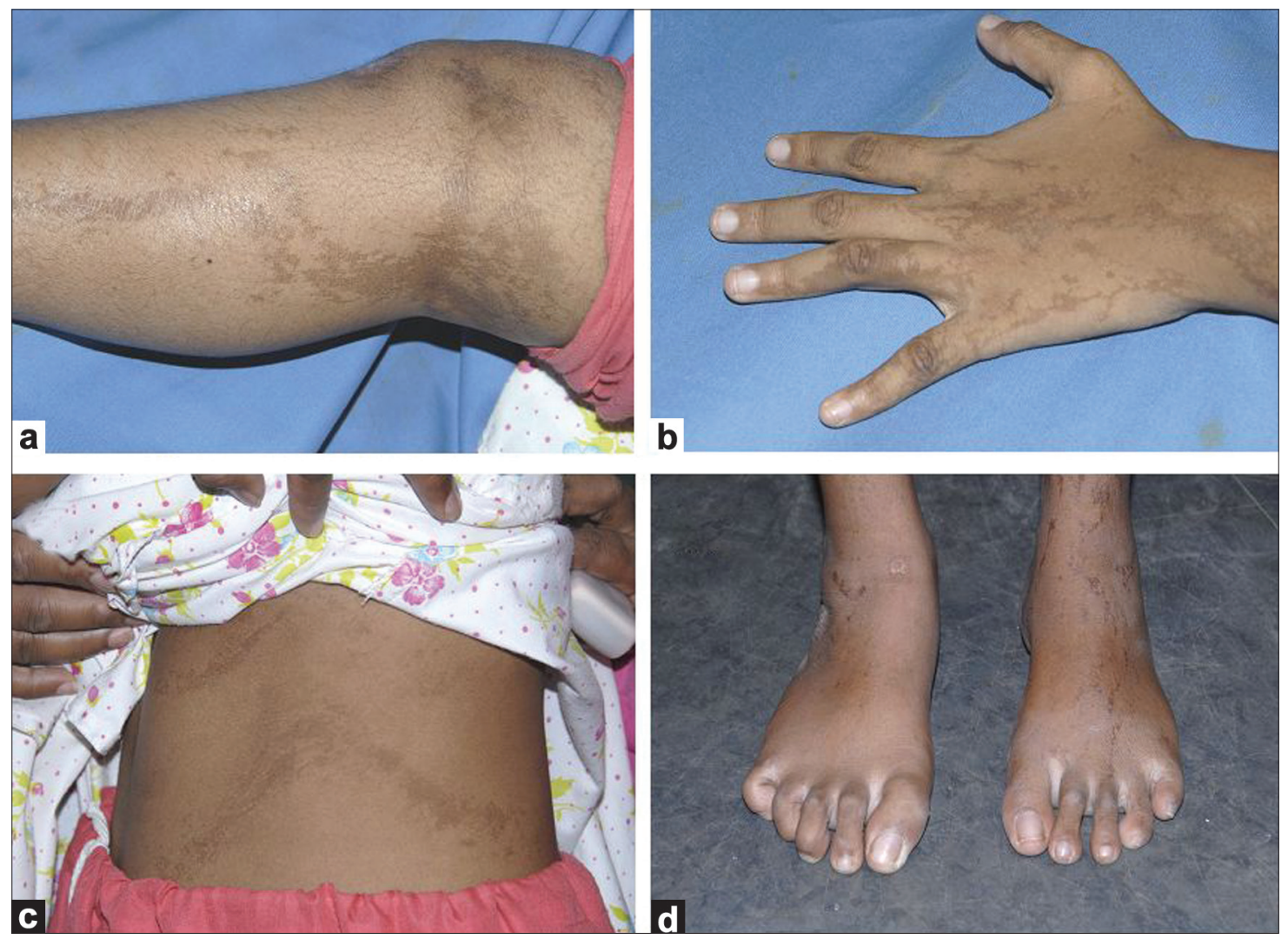

Figure 1: (a-c) Hyperpigmentation along the lines of Blaschko over the left leg, hand and trunk, some showing a Chinese check-board pattern, (d) Hammer toes, early pes cavus and pigmentation of the left foot
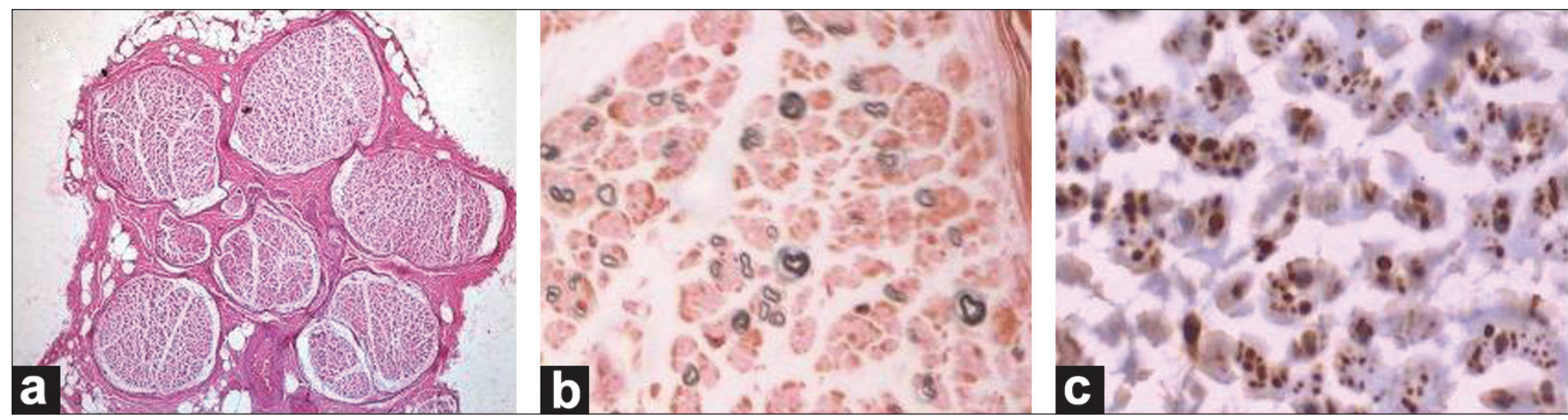

Figure 2: Histopathology of left sural nerve shows: (a) Features of chronic uniform axonopathy with mild regenerative activity (H and $E$ stain, $\times 50)$, (b) Higher magnification reveals predominant loss of large myelinated fiber with occasional regenerating cluster (K-pal stain for myelin, $\times 320$ ),

(c) Neurofilament immunostaining for axons highlights the depletion of large diameter axons. Regenerative axonal sprouting is visible as clusters of dot like brown staining of the smaller diameter axons (Neurofilament Immunohistochemistry, $\times 320$ ) 
symptoms manifest in early childhood. Though IP is a relatively non-progressive disorder, this late presentation may either suggest a later detection only after significant weakness has set in or a more progressive course of IP.

\section{Sanju P. Joy, Samhita Panda, Girish B. Kulkarni, Pramod Kumar Pal, Yasha T. Chickabasaviah', Rajani R. Battu ${ }^{2}$}

Departments of Neurology, ${ }^{1}$ Neuropathology, National Institute of Mental Health and Neurosciences, ${ }^{2}$ Vitreoretinal Services, Narayana Netralaya, Bangalore, India. E-mail: pal.pramod@rediffmail.com

\section{References}

DOI: $10.4103 / 0028-3886.59490$

1. Landy SJ, Donnai D. Incontinentia pigmenti (Bloch-Sulzberger syndrome). J Med Genet 1993;30:53-9.

2. Pinheiro A, Mathew MC, Thomas M, Jacob M, Srivastava VM, Cherian $\mathrm{R}$, et al. The clinical profile of children in India with pigmentary anomalies along the lines of Blaschko and central nervous system manifestations. Pediatr Dermatol 2007;24:11-7.

3. Hadj-Rabia S, Froidevaux D, Bodak N, Hamel-Teillac D, Smahi A, Touil Y, et al. Clinical study of 40 eases of incontinentia pigmenti Arch Dermatol 2003;139:1163-70.

4. Halata Z, Grim M, Christ B. Origin of spinal cord meninges, sheaths of peripheral nerves, and cutaneous receptors including Merkel cells. An experimental and ultrastructural study with avian chimeras Anat Embryol (Berl) 1990;182:529-37.

Accepted on 09-10-2009 